\title{
Key anxiety factors for buying an electric vehicle
}

\author{
Adrian TANȚĂU \\ The Bucharest University of Economic Studies \\ adrian.tantau@fabiz.ase.ro \\ Ileana GAVRILESCU \\ The Bucharest University of Economic Studies \\ gavrilescu_ileana@yahoo.com
}

\begin{abstract}
The purchase of an electric vehicle has become a widely debated topic by the economic community in recent years. However, few personal automobile users, who purchased new cars, have chosen a fully electric vehicle. The novelty of this research came from the assumption that there is a lack of knowledge in this field and fuelled by contradicting information. Potential electric vehicle buyers have developed a real psychosis on the subject, the most consistent motives being among others the charge anxiety. Many researchers consider that the worries of the vehicle users are exaggerated and are not based on reality. Better documentation of the subject would reduce these fears and would increase the process of electrical vehicles absorption. The main objective of this article is to analyse the main anxiety factors by buying an electric vehicle and to reduce the related anxiety. For this purpose, the authors have performed an econometric analysis based on a questionnaire distributed online and face to face in Romania.
\end{abstract}

Keywords: range anxiety, purchasing barriers, electric vehicles, sustainability, business models.

\section{Introduction}

Over the past ten years, since electric vehicles have started being mass sold, they have been continuously perfected. Therefore, their dynamic performances, the range, the recharge autonomy, and passive safety have recently reached the performance of traditional vehicles, powered by Internal Combustion Engines (ICE). At the same time, remarkable progress has been made regarding the electrical recharge of electric vehicles and their commercialisation.

Unfortunately, following the academic literature pertaining to the present research, but also the reality reflected by the public opinion there are traditional purchasing barriers for electric vehicles (He, et al, 2019, o Neil et al, 2019).

The price of the acquisition being too high, the dynamic performance reduced, the range being reduced, the producers offer poor, the recharging too complex or too expensive, the services being still in an initial phase, are the main factors that are present in studies regarding purchasing of electric mobility. Electric vehicles (EV)absorption advances significantly slower and the highly politically debated sustainability scientific revolution is not going through its programmed destiny, respectively with the anticipated speed or even the one established through large local or internationally adopted schemes and legislation. The concerned entrepreneurship has not innovated its business strategy, and thus far has not eliminated the adoption barriers. That is why it comes to no surprise that world $\mathrm{CO}_{2}$ emissions have continued to increase and will continue to increase for the following 10 years.

The electricity markets experienced important evolutions in Romania in the past five years, both in terms of size and prices, developments based on both structural and behavioural factors.

The following research has aimed at analysing the weights of the electric mobility absorption barriers reflected in the potential buyer's mentality and finding significant 
factors that would predict purchase interest. The main objective of this article is to analyse the key anxiety factors by buying an electric vehicle and to reduce the related anxiety.

Specifically, in the methodology chapter, each barrier and factor has been framed as a hypothesis and multiple questions have been allocated to proving and quantifying the weight. After arranging the data, we proceeded to analyse and interpret them in the results section.

\section{Literature Review}

Over time, the fundamental specific research has strived to dismantle the negative arguments of adopting electric mobility invoked obsessively by potential users or by detractors, including the causes of range anxiety (Patt, et al., 2019). Unfortunately, in multiple cases, the dismantling of barriers has not been done according to reality, but rather from an optimistic perspective of what was next to come.

Regarding this subject, new business models for e-mobility should enable us to examine the relative impacts of different purchase factors with different policies, technology development and prices (Schwartz et al., 2017).

Recent studies have underlined that the mass majority of drivers don't travel daily more than the maximum range provided by a full charge due to a high degree of anxiety. In these studies, anxiety represents the fear of the battery running out before having the possibility of recharge it. Range Anxiety introduces the idea that the buyers are psychologically sensitive to the limited range of an EV (Noel et al., 2019). The range anxiety is defined as the driver's fear of remaining stranded on the road before arriving to the location due to an empty battery (Salah\&Kama, 2017).

With respect to anxiety, the research and the scientific debates dedicated to sustainable development related to the adoption of EV have shown much interest in the relatively low performance and the initially high relative cost of an electric car. A similarly paradoxical situation was registered in 2011 in America where only a few persons had a real interest in analysing and understanding the differences between new hybrid and electric cars (Cholia, 2011).

On the other hand, a survey from 2018 stipulates that $83 \%$ of the respondents would buy an electric vehicle when they have to change the classic one (Fossdyke, 2018).

However, other examples of surveys demonstrate the inconsistency in questionnaire answers due to different competent research standards (Wittenberg, 2016). There are a lot of debates between academicians and practicians regarding competent standards for research (Dima, A., \& Vasilache, S. 2016).

There are consumers with greater knowledge or experience, which are more likely to value electric vehicles, and such a vehicle would be a viable future purchase option. Therefore, these consumers are willing to pay a premium for e-mobility (Jin \& Slowik, 2017).

Regarding the most influential barriers for purchasing an electric car, there are several factors that influence this process, such as: EVs are expensive, public recharging infrastructure is poor, batteries are not enough technologically developed (Carley, 2013).

The techno-scientific research has a relatively linear time dependence concerning the producing an electrical vehicle and the generation of the electricity necessary for charging it (Busu M. et al, 2019).

The research for recharging options has a high technical complexity and a higher dependence on the personal psychological relativism of the mobility buyers and the buying process as itself. Due to that, the innovation in the recharging field would require from an entrepreneurship perspective, a true revolution. But the so-called innovation in 
the business models for electric mobility has proven to be rather an ingrate dressing of the old models. There is a need for new business models for e-mobility and also new policies in this field.

\section{Methodology}

According to the literature review (Simsekoglu, 2018) buying a EV is a problem influenced by many factors such as: cost of acquisition (many times after applying stimulus for buying), range autonomy, recharge autonomy (which includes the availability of recharging stations, the time required for a recharge and the compatibility of the charging devices), the dynamic performance of the car, long term savings and the buyer's degree of knowledge of the field.

By reviewing the literature on the barriers of adopting electric mobility and correlated to the one centred on anxiety about electric cars, but based also on our own previous research, we have established that the most important aspects of the state of anxiety, developed by potential buyers, that reduce their appetite for electric cars, would be the following:

- the fear that one will not be able to reach its destination due to the depletion of the battery (ie "distance anxiety")

- the fear that a charging point cannot be found anywhere and at any time, or that the machine's power cord plug may be incompatible with the target charging socket outlet (ie "charging anxiety"),

- the fear that due to unpredictable situations the working agenda on that day could be disturbed (ie "anxiety of aggravation of the everyday program),

- the fear that overloading the utility network could interrupt the operation of home lighting and electrical appliances- such as a refrigerator, air conditioning, TV, computer, etc. (ie "anxiety of damage"),

- the fear that the car coupled to the power outlet would not be charged (or "hazard anxieties") or could cause a fire in the car (ie, "anxiety of fire"),

- the fear that certain distance travelled (ie "constrained freedom anxiety") will no longer be possible,

- other fears more or less vaguely resonant in the mental - and this without having exhausted the entire specific motivational palette.

The conception of the questionnaire was done by consulting 10 people - five specialists and five non-specialists (including a sociologist and a psychologist), who provided constructive ideas for the most appropriate questions. Questionnaire distribution and appropriate response collection started on 1 January 2018 and the closure of the investigation ended on 31 December 2018 and it focused on Romanian respondents.

Starting from the idea that those who are the most justified for the investigation of this research, are the ones most well-informed in the field, we decided that the sample of respondents to our survey should be mobility buyers who after 1 January 2016 and until December 31, 2017 replaced their old cars with some ICE-powered engines, not opting for EVs. At the preparatory stage of the survey, we ran a list of over 550 potential respondents. However, our ambition to combine the written questionnaire with the direct interview for as many as possible cases has been hampered by the spread of the respondents over a broad geographic area and by the mismatches of working agendas. However, due to favourable touristic opportunities and friendly visits throughout 2018, all questionnaires were interviewed by a team of three operators. Even the six atypical cases were consumed in real-time, Skype and Whats-app. Therefore, they cannot be 
considered defective or inappropriate for the intended purpose. At the end of the campaign, 249 completed questionnaires were collected, but after their technical purification (incomplete or indescribable answers), only 225 remained fully operational.

To increase the operational efficiency of the survey, the simultaneous-alternative combination of two specific tools was used: filling in the written questionnaire with the direct interview. This method - the combined interview - may risk the so-called "operator effect" - that the interviewer should look for the influence of the investigator on answers if the operator does not have the tact of avoiding such a trap every time. The dialogue produced by the "reporter" to the respondent must, of course, revolve around the subject of the interview keeping in mind that the questions and the replies must neither repeat the questions in the written questionnaire nor suggest in some way different answers. The direct part of the survey consists of a "depth interview" - with discussions centred on electric mobility with the tactic being "semi-structured" - with free elaboration, adapted to the context and circumstances. The combined interview is rather the consumption of two questionnaires at the same time, but other components of the survey are involved. For example, through our physical presence and empathic behaviour, we have, for the most part, managed to create an open state for the interviewee - very appropriate to this kind of situation, but at the same time sufficiently focused on good acquisition of the content of the questions, and correspondingly - on the good elaboration of the answers. Although it presents some difficulties and disadvantages, this method - which we tested and utilised during other investigations, but never systematically applied as presented now, proved to be far more effective than the standard alternative.

The questionnaire was designed with 50 questions, of all types. Some general questions, control questions, and questions of knowledge - which specifically concerned the interviewer's degree of knowledge about mobility, were intertwined with questions of opinion-whether closed, semi-open, or open-minded - which focused on the relative importance of barriers which prevented the interviewed from considering the option of purchasing an electric car. Some questions required a single answer, other questions could be answered with multiple answers. Questions addressing the absorption barriers and the interest in buying BEV cars were modelled using a Likert scale with 7 points (1 completely unimportant, 7 - very important). This scale can be used in statistical methods with greater confidence, and the results of these statistical methods have a very high degree of accuracy. Thus, the statistical hypotheses tested in our analysis are:

- H1: Range anxiety has a negative impact on the purchase interest of an electric car;

- H2: Battery charging anxiety has a negative impact on the purchase interest of an electric car

- H3: The high purchase price has a negative impact on the purchase interest of an electric car;

- H4: The inadequacy and lack of opportunity of the offer have a negative impact on the purchase interest of an electric car;

- H5: Distrust in EV technology has a negative impact on the purchase interest of an electric car;

- H6: Subsequent unpredictable cost anxiety has a negative impact on the purchase of an electric car;

- H7: Mistrust in servicing has a negative impact on the purchase interest of an electric car;

- H8: Lack of personal knowledge in the field has a negative impact on the purchase interest of an electric car; 
- H9: The lack of personal experience with respect to EV has a negative impact on the purchase interest of an electric car;

- H10: Age is a determining factor in buying an electric car;

- H11: Monthly income is a significant factor in buying an electric car.

\section{Results}

Starting from the research studies mentioned in the previous chapter, we focus on the subject of our paper and formulate the research question: "What are the barriers preventing the purchase of an electric car?" In addition to what has been done in this area of research, we will try to estimate which of the nine exogenous factors mentioned above have the greatest impact on the endogenous variable in the multilinear regression model.

The factors that determine the purchase of an electric car have been studied by many economists. Thus, (Lopes et al., 2010) demonstrates that the purchase price, distance autonomy and battery charging time have a direct and powerful impact in choosing to purchase an electric car. Other authors (Nykvist and Nilsson, 2015) argue that the purchase of an electric car is mainly driven by the car's dynamic performance, the long-term financial economy and the buyer's knowledge of the field.

The econometric model will include a dependent variable and 11 independent variables.

$$
y=\beta_{0}+\sum_{i=1}^{9} \beta_{i} \cdot x_{i}+\varepsilon
$$

where,

- $\mathrm{y}=$ endogen variable

- $x i=$ exogen variables

- $\beta \mathrm{i}=$ model parameters

- $\varepsilon=$ residual variable

The variables which will be used to create the econometric model come from quantifying the hypotheses described above. The values are based on a Likert scale from completely unimportant - 1 to completely important 7 . The statistical description of the variables used in can be found in Table 1, while the correlation matrix is shown in Table 2. It can be seen that in general, the respondents consider the most important barriers to be in decreasing order of importance, the ones that follow variables X2, X3, X2 and X7. This confirms previous research that argues that range anxiety, charging battery anxiety, purchase price and the mistrust in servicing are important barriers in electric vehicle adoption.

Table 1. Description of the variables used in the model

\begin{tabular}{|c|c|c|c|}
\hline & Mean & Std. Deviation & $\mathbf{N}$ \\
\hline $\mathrm{y}$ & 4.27 & 1.895 & 225 \\
\hline $\mathrm{X} 1$ & 6.08 & 1.240 & 225 \\
\hline $\mathrm{X} 3$ & 5.71 & 1.131 & 225 \\
\hline $\mathrm{X} 4$ & 6.11 & 1.102 & 225 \\
\hline $\mathrm{X} 5$ & 4.46 & 1.690 & 225 \\
\hline $\mathrm{X} 6$ & 4.32 & 1.594 & 225 \\
\hline $\mathrm{X} 7$ & 4.71 & 1.639 & 225 \\
\hline $\mathrm{X} 8$ & 5.23 & 1.714 & 225 \\
\hline $\mathrm{X} 9$ & 4.84 & 1.902 & 225 \\
\hline $\mathrm{X} 10$ & 4.85 & 1.864 & 225 \\
\hline
\end{tabular}


Source: Author's values determined using the SPSS 22 software package

Table 2. Matrix of Pearson correlation coefficients

\begin{tabular}{|c|c|c|c|c|c|c|c|c|c|c|c|c|}
\hline Variable & $\mathbf{y}$ & $\mathrm{X1}$ & $\mathrm{x2}$ & $\mathrm{X3}$ & $\mathrm{X} 4$ & $\mathrm{X5}$ & $\mathrm{X} 6$ & $\mathrm{X7}$ & $\mathrm{X} 8$ & $\times 9$ & $\mathrm{X10}$ & $\mathrm{X11}$ \\
\hline $\mathbf{y}$ & 1 & -0.15 & -0.13 & -0.01 & 0.105 & -0.23 & -0.16 & -0.14 & -0.12 & 0.103 & -0.16 & 0.188 \\
\hline $\mathrm{X1}$ & -0.15 & 1 & 0.39 & 0.196 & 0.066 & 0.246 & 0.119 & 0.118 & 0.17 & 0.115 & 0.091 & 0.017 \\
\hline $\mathrm{X} 2$ & -0.13 & 0.39 & 1 & 0.32 & 0.464 & 0.593 & 0.472 & 0.53 & 0.526 & 0.34 & 0.055 & -0.13 \\
\hline $\mathrm{X} 3$ & -0.01 & 0.2 & 0.32 & 1 & 0.166 & 0.23 & 0.22 & 0.228 & 0.207 & 0.232 & -0.06 & -0.17 \\
\hline$X 4$ & 0.105 & 0.07 & 0.464 & 0.166 & 1 & 0.584 & 0.555 & 0.535 & 0.633 & 0.655 & 0.013 & -0.15 \\
\hline X5 & -0.23 & 0.25 & 0.593 & 0.23 & 0.584 & 1 & 0.692 & 0.619 & 0.659 & 0.477 & 0.012 & -0.19 \\
\hline $\mathrm{X6}$ & -0.16 & 0.12 & 0.472 & 0.22 & 0.555 & 0.692 & 1 & 0.651 & 0.583 & 0.406 & 0.004 & -0.3 \\
\hline $\mathrm{X7}$ & -0.14 & 0.12 & 0.53 & 0.228 & 0.535 & 0.619 & 0.651 & 1 & 0.691 & 0.382 & -0.04 & -0.27 \\
\hline $\mathrm{X8}$ & -0.12 & 0.17 & 0.526 & 0.207 & 0.633 & 0.659 & 0.583 & 0.691 & 1 & 0.539 & 0.039 & -0.23 \\
\hline X9 & 0.103 & 0.12 & 0.34 & 0.232 & 0.655 & 0.477 & 0.406 & 0.382 & 0.539 & 1 & -0 & -0.13 \\
\hline $\mathrm{X10}$ & -0.16 & 0.09 & 0.055 & -0.06 & 0.013 & 0.012 & 0.004 & -0.04 & 0.039 & -0 & 1 & 0.241 \\
\hline X11 & 0.188 & 0.02 & -0.13 & -0.17 & -0.15 & -0.19 & -0.3 & -0.27 & -0.23 & -0.13 & 0.241 & 1 \\
\hline
\end{tabular}

Source: Author's values determined using the SPSS 22 software package

Table 3. Matrix of Pearson correlation coefficients significance

\begin{tabular}{|c|c|c|c|c|c|c|c|c|c|c|c|c|}
\hline Variable & $\mathbf{y}$ & $\mathbf{X 1}$ & $\mathbf{X 2}$ & $\mathbf{X 3}$ & $\mathbf{X 4}$ & $\mathbf{X 5}$ & $\mathbf{X 6}$ & $\mathbf{X 7}$ & $\mathbf{X 8}$ & $\mathbf{X 9}$ & $\mathbf{X 1 0}$ & $\mathbf{X 1 1}$ \\
\hline $\mathbf{y}$ &. & .012 & .023 & .466 & .058 & .000 & .008 & .018 & .038 & .061 & .007 & .002 \\
\hline $\mathbf{X 1}$ & .012 &. & .000 & .002 & .162 & .000 & .037 & .038 & .005 & .042 & .088 & .402 \\
\hline $\mathbf{X 2}$ & .023 & .000 &. & .000 & .000 & .000 & .000 & .000 & .000 & .000 & .206 & .031 \\
\hline $\mathbf{X 3}$ & .466 & .002 & .000 &. & .006 & .000 & .000 & .000 & .001 & .000 & .196 & .005 \\
\hline $\mathbf{X 4}$ & .058 & .162 & .000 & .006 &. & .000 & .000 & .000 & .000 & .000 & .421 & .014 \\
\hline $\mathbf{X 5}$ & .000 & .000 & .000 & .000 & .000 &. & .000 & .000 & .000 & .000 & .427 & .002 \\
\hline $\mathbf{X 6}$ & .008 & .037 & .000 & .000 & .000 & .000 &. & .000 & .000 & .000 & .478 & .000 \\
\hline $\mathbf{X 7}$ & .018 & .038 & .000 & .000 & .000 & .000 & .000 &. & .000 & .000 & .269 & .000 \\
\hline $\mathbf{X 8}$ & .038 & .005 & .000 & .001 & .000 & .000 & .000 & .000 &. & .000 & .282 & .000 \\
\hline $\mathbf{X 9}$ & .061 & .042 & .000 & .000 & .000 & .000 & .000 & .000 & .000 &. & .491 & .030 \\
\hline $\mathbf{X 1 0}$ & .007 & .088 & .206 & .196 & .421 & .427 & .478 & .269 & .282 & .491 &. & .000 \\
\hline $\mathbf{X 1 1}$ & .002 & .402 & .031 & .005 & .014 & .002 & .000 & .000 & .000 & .030 & .000 &. \\
\hline
\end{tabular}

The correlation table (Table 2) reveals that there is a strong and direct correlation between the independent variable on one side and the dependent variables on the other side - used in the econometric model. Moreover, the degree of correlation between independent variables is relatively low, none of them having a correlation higher than 0.5. Table 3 shows that the Pearson Correlations are statistically significant with the exception of X3, X4, and X9.

The econometric multilinear regression model was estimated by the smallest squares method (OLS), and the method used is ENTER. Through this process, out of the 11 exogenous barriers chosen by the authors, only 4 were found to be significant predictors. The description of the econometric model can be seen in Table 4, while Table 5 is the ANOVA table, and Table 6 shows the coefficients of the regression model.

Table 4. Description of the multilinear regression model 


\begin{tabular}{|c|c|c|c|c|c|c|c|c|c|c|}
\hline \multirow[b]{2}{*}{ Model } & \multirow[b]{2}{*}{$\mathbf{R}$} & \multirow[b]{2}{*}{$\begin{array}{c}\mathbf{R} \\
\text { Square }\end{array}$} & \multirow[b]{2}{*}{$\begin{array}{l}\text { Adjusted } \\
\text { R Square }\end{array}$} & \multirow{2}{*}{$\begin{array}{c}\text { Std. } \\
\text { Error of } \\
\text { the } \\
\text { Estimate }\end{array}$} & \multicolumn{5}{|c|}{ Change Statistics } & \multirow[t]{2}{*}{$\begin{array}{l}\text { Durbin- } \\
\text { Watson }\end{array}$} \\
\hline & & & & & $\begin{array}{c}\text { R } \\
\text { Square } \\
\text { Change }\end{array}$ & $\begin{array}{c}\mathbf{F} \\
\text { Change }\end{array}$ & df1 & df2 & $\begin{array}{l}\text { Sig. F } \\
\text { Change }\end{array}$ & \\
\hline 1 & .479 & 0.229 & 0.190 & 1.705 & 0.229 & 4.767 & 11 & 213 & .000 & 2.271 \\
\hline
\end{tabular}

Table 5. Anova Table

\begin{tabular}{|l|l|l|l|l|l|l|}
\hline & Model & $\begin{array}{l}\text { Sum of } \\
\text { Squares }\end{array}$ & df & $\begin{array}{l}\text { Mean } \\
\text { Square }\end{array}$ & F & Sig. \\
\hline 1 & Regression & 184.510 & 11 & 16.774 & 5.767 & .000 \\
\hline & Residual & 619.490 & 213 & 2.908 & & \\
\hline & Total & 804.000 & 224 & & & \\
\hline
\end{tabular}

Source: Author's values determined using the SPSS 22 software package

Table 6. Multilinear regression model

\begin{tabular}{|c|c|c|c|c|c|c|c|c|c|c|}
\hline \multirow{2}{*}{ Model } & & \multicolumn{2}{|c|}{$\begin{array}{l}\text { Unstandardized } \\
\text { Coefficients }\end{array}$} & \multirow{2}{*}{$\begin{array}{l}\text { Standardized } \\
\text { Coefficients } \\
\text { Beta }\end{array}$} & \multirow{2}{*}{$\mathbf{t}$} & \multirow{2}{*}{ Sig. } & \multicolumn{4}{|c|}{ Collinearity Statistics } \\
\hline & & B & $\begin{array}{l}\text { Std. } \\
\text { Error }\end{array}$ & & & & Partial & Part & Tolerance & VIF \\
\hline \multirow{12}{*}{1} & (Constant) & 4.703 & .910 & & 5.170 & .000 & & & & \\
\hline & $\mathrm{X} 1$ & -.117 & .103 & -.076 & -1.136 & .257 & -.078 & -.068 & .798 & 1.253 \\
\hline & $X 2$ & -.021 & .142 & -.012 & -.146 & .884 & -.010 & -.009 & .501 & 1.994 \\
\hline & $\mathrm{X} 3$ & .102 & .112 & .059 & .910 & .364 & .062 & .055 & .848 & 1.180 \\
\hline & $X 4$ & .366 & .106 & .327 & 3.449 & .001 & .230 & .207 & .403 & 2.478 \\
\hline & $\mathrm{X} 5$ & -.400 & .118 & -.336 & -3.373 & .001 & -.225 & -.203 & .364 & 2.748 \\
\hline & $\times 6$ & -.037 & .108 & -.032 & -.342 & .733 & -.023 & -.021 & .411 & 2.434 \\
\hline & $\mathrm{X7}$ & -.049 & .105 & -.044 & -.465 & .642 & -.032 & -.028 & .400 & 2.502 \\
\hline & $\mathrm{X} 8$ & -.065 & .099 & -.065 & -.653 & .515 & -.045 & -.039 & .367 & 2.725 \\
\hline & $X 9$ & .143 & .085 & .140 & 1.687 & .093 & .115 & .101 & .522 & 1.915 \\
\hline & $\mathrm{X} 10$ & -.316 & .098 & -.202 & -3.219 & .001 & -.215 & -.194 & .916 & 1.092 \\
\hline & $\mathrm{X} 11$ & .225 & .070 & .213 & 3.211 & .002 & .215 & .193 & .823 & 1.215 \\
\hline
\end{tabular}

Source: Author's values determined using the SPSS 22 software package

As we can see from Table 5 , the regression model is statistically significant $(\mathrm{F}=$ 5.767; Sig. $=0.000)$. Also, the correlation coefficient $(R=0.479)$ reveals that the dependent variable is very correlated with the independent variables and the coefficient of determination (R-square $=0.229$ ) shows that $22.9 \%$ of the variation of the dependent variable is explained by the variation of the independent variables. In addition, the Durbin-Watson test ( $\mathrm{DW}=2,271$ ) has a value close to 2 , which means that the regression equation has no autocorrelation problems.

We can also see from Table 6 which of the independent variables in the model are significant (Sig. <0.05). Moreover, since all variance inflection factors (VIF) are related to the exogenous variables are less than 3 and all the tolerance values are over 0.4 , we conclude that there is no collinearity between the exogenous variables. The multiple linear regression equation obtained using the SPSS software is:

$$
y=4.370+0.366 \cdot x_{4}-.400 \cdot x_{5}-0.316 \cdot x_{10}+0.225 \cdot x_{11}
$$

Thus, we can conclude that of the eleven statistical assumptions, four were accepted (H4, H5, H10 and H11), while seven were rejected (H1, H2, H3, H6, H7, H8 and H9). The significant factors that can be used as predictors of the buying interest of an 
electric car are: monthly income, inadequacy and lack of opportunity of the offer, age segment, and distrust of EV technology. Lack of EV experience has a value of significance of 0.093 and although it doesn't reach significance, it is the closest barrier that could be considered as a predictor of electric vehicles purchase interest.

\section{Conclusions}

After reviewing the trade academic literature, but also based on our analysis, we arrived at the conclusion that among the absorption barriers and anxiety factors related to purchasing an electric vehicle, a considerable share is still borne out by the potential buyers' lack of knowledge of the characteristics and advantages of this type of automobile. It is also shown that the purchase price, distance autonomy and battery charging time are the most important barriers preventing the purchase of an electric car. This research has shown that the main barriers and anxiety factors of purchasing electric vehicles in Romania are: inadequacy and lack of opportunity of the offer of electric cars and distrust of EV technology. Other factors include age and monthly income of buyers.

The econometric model reveals that an increase of 1 percentage point (pp) of the monthly income will lead to an increase of $0.225 \mathrm{pp}$ in the desire to buy an electric car and a $1 \mathrm{pp}$ increase in the inadequacy and lack of opportunity of the offer will lead to an increase $0.366 \mathrm{pp}$ of the desire to buy an electric car. An increase in the desire to buy an electric car caused by the increase in the importance of the inadequacy and lack of opportunity of the offer can be explained by the fact that people interested in electric cars would like a better offer, not supported at the moment by the current traders. At the same time, an increase of $1 \mathrm{pp}$ in the age segment implies a decrease of $0.316 \mathrm{pp}$ of the desire to buy an electric car. The degree of confidence in EV technology is proportional to the desire to buy an EV. Out of these barriers, the most significant one is represented by the lack of confidence in EV technology, 1pp increase in lack of confidence leading to a 0.400 decrease in interest to buy an electric vehicle.

The article's conclusions are consistent with previous research and confirm the fact that in Romania, range anxiety, charging anxiety, high purchase price, and servicing mistrust are important barriers. Factors such as monthly income, age, inadequacy and lack of opportunity of the offer, lack of trust in EV technology can be used with confidence as predictors of the purchasing interest of an electric vehicle.

\section{References}

Busu, M., Clodnițchi, R., \& Mureșan, M. L. (2019). A correlation analysis of the spot market prices of the Romanian electricity sector. Management \& Marketing. Challenges for the Knowledge Society, 14(1), 150-162.

Cholia, A., 2011, "Most Americans confused about plug-in hybrid, electric vehicles, survey says.", https://www.zdnet.com/article/most-americans-confused-aboutplug-in-hybrid-electric-vehicles-survey-says/, accessed 20. May 2019.

Dima, A., \& Vasilache, S. (2016). Trends in the internationalization of European higher education in a convergence perspective, Management \& Marketing, 11(2), 449457. doi: https://doi.org/10.1515/mmcks-2016-0008.

Fossdyke, J., 2018, "Poll - 83\% Of Respondents Will Consider Going Electric With Next Vehicle.",https://insideevs.com/poll-83-of-respondents-will-consider-goingelectric-with-next-vehicle/, accessed on 21 May 2019.

He X., Zhan W., Hu Y (2019) Consumer purchase intention of electric vehicles in China: The roles of perception and personality, Journal of Cleaner Production, Vol. 204, 10601069. 
Jin, L., Slowik, P., 2017, "Literature review of electric vehicle consumer awareness and outreach activities",

https://www.theicct.org/sites/default/files/publications/Consumer-EVAwareness_ICCT_Working-Paper_23032017_vF.pdf, Accessed on 21 May 2019.

Krause, R.M., Carley, S.R., Lane, B.W., Graham, J.D. (2013) Perception and reality: Public knowledge of plug-in electric vehicles in 21 U.S. cities. Energy Policy, vol. 63, pp. 433-440.

J. A. P., Soares, F. J., \& Almeida, P. M. R. (2010). Integration of electric vehicles in the electric power system. Proceedings of the IEEE, 99(1), 168-183.

Miwa, T., Sato, H., Takayuki Morikawa, T., 2017, "Range and Battery Depletion Concerns with Electric Vehicles", Hindawi - Journal of Advanced Transportation, Volume 3, Article ID 7491234, 12.

Nykvist, B., \& Nilsson, M. (2015). Rapidly falling costs of battery packs for electric vehicles. Nature climate change, Vol. 5, Issue 4, 329.

Noel L., Zarazua de Rubens G., Sovacool B., Kester J. (2019) Fear and loathing of electric vehicles: The reactionary rhetoric of range anxiety, Energy Research \& Social Science, Vol. 48, 96-107.

O'Neill E., Moore D., Kelleher L., Brereton F. (2019) Barriers to electric vehicles uptake in Ireland: Perspectives of car-dealers and policy-makers, Case Studies on Transport Policy, Vol. 7, Issue 1, pp. 118-127.

Patt A., Aplyn D., Weyrich P., Oscar van Vliet (2019) Availability of private charging infrastructure influences readinessto buy electric cars, Transportation Research, Part A, 125, 1-7.

Salah K., Kama N., 2017Inter-service provider charging protocol: a solution to address range anxiety of electric vehicle owners, Energy Procedia, 136, 157-162

Schwartz, L.C., Wei, M., Morrow, W.R., Deason, J., Schiller, S.R., Leventis, G., Smith, S.J., Leow, W.L., Levin, T., Plotkin, S., Zhou, Y., Teng, J., 2017, "Electricity end uses, energy efficiency, and distributed energy resources baseline", LBNL Report Number (LBNL- 1006983), https://emp.lbl.gov/publications/electricity-enduses-energy.

Simsekoglu 0., 2018, Socio-demographic characteristics, psychological factors and knowledge related to electric car use: A comparison between electric and conventional car drivers, Transport Policy, Volume 72, pp. 180-18. 